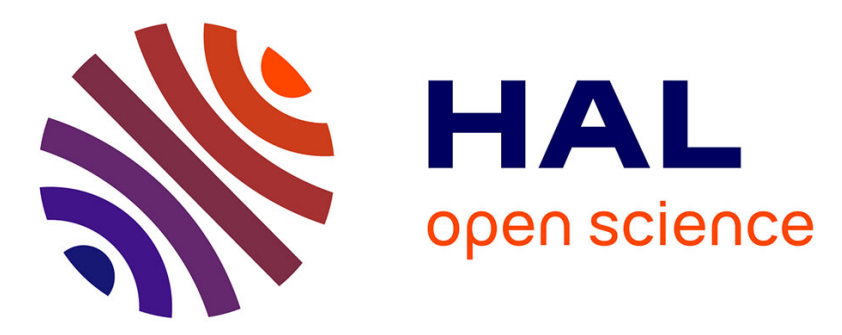

\title{
Survey and performance evaluation on some automotive semi-active suspension control methods: A comparative study on a single-corner model
}

Charles Poussot-Vassal, Cristiano Spelta, Olivier Sename, Sergio Savaresi, Luc Dugard

\section{To cite this version:}

Charles Poussot-Vassal, Cristiano Spelta, Olivier Sename, Sergio Savaresi, Luc Dugard. Survey and performance evaluation on some automotive semi-active suspension control methods: A comparative study on a single-corner model. Annual Reviews in Control, 2012, 36 (1), pp.148-160. 10.1016/j.arcontrol.2012.03.011 . hal-00733261

\section{HAL Id: hal-00733261 \\ https://hal.science/hal-00733261}

Submitted on 18 Sep 2012

HAL is a multi-disciplinary open access archive for the deposit and dissemination of scientific research documents, whether they are published or not. The documents may come from teaching and research institutions in France or abroad, or from public or private research centers.
L'archive ouverte pluridisciplinaire HAL, est destinée au dépôt et à la diffusion de documents scientifiques de niveau recherche, publiés ou non, émanant des établissements d'enseignement et de recherche français ou étrangers, des laboratoires publics ou privés. 


\title{
Survey and Performance Evaluation on Some Automotive Semi-Active Suspension Control Methods: a Comparative Study on a Single-Corner Model
}

\author{
C. Poussot-Vassal ${ }^{a, *}$, C. Spelta ${ }^{\mathrm{b}}$, O. Sename ${ }^{\mathrm{c}}$, S.M. Savaresi ${ }^{\mathrm{d}}$, L. Dugard $^{\mathrm{c}}$ \\ ${ }^{a}$ Onera - The French Aerospace Lab, F-31055 Toulouse, France. \\ ${ }^{b}$ Dipartimento di Ingegneria dell'Informazione e Metodi Matematici, Università degli Studi di Bergamo, Italy \\ ${ }^{c}$ GIPSA-lab Control Systems department, Grenoble, France. \\ ${ }^{d}$ Dipartimento di Elett. e Informazione, Politecnico di Milano, Italy.
}

\begin{abstract}
In this paper, an overview and a benchmark of some semi-active suspension control strategy performances is proposed. Based on a recent result of the authors, where the optimal semi-active performance trade-off was addressed, here, a complete benchmark to evaluate any controlled semi-active suspensions is proposed, and applied on different control approaches. The present paper aims at providing a picture - as complete as possible - of the present state of the art in the semi-active suspension control field in terms of comfort and road-holding performance evaluation and trade-off.
\end{abstract}

Keywords: Semi-active suspension control, Performance evaluation, Benchmark.

\section{Introduction}

\subsection{Motivations and framework}

Due to the increasing mobility requirements, wheeled vehicles are subject to a lot of attention. Indeed, the forthcoming economical (e.g. cost reduction), ecological (e.g. greener systems) and social (e.g. safety) challenges within this high potential field of application has led the development of ever more efficient technological and methodological solutions from both academic and industrial researchers. Among all sub-systems affecting the road vehicles dynamical behaviour (e.g. brakes, steering, motor, throttle, suspensions...) semi-active suspensions have received a lot of attention since it the suspension systems play a key role in the overall vehicle dynamics since it provides a link between the wheel and the chassis (either for a 4-3-2-wheeled vehicle) and is thus crucial for both passenger safety and comfort; indeed, suspensions are being more and more included in the so-called global chassis control. More specifically, they provide the best compromise between cost (energy consumption, actuators, sensors hardware) and performances (safety and comfort requirements). Within this specific field, the research follows two mainstreams: the study of new technologies of semi-active damping actuators (e.g. electro hydraulic, electro rheological and magneto rheological damper), and the design of dedicated semi-active control strategies (see e.g. Hrovat

\footnotetext{
* Corresponding author

Email address: charles.poussot-vassal@onera.fr (C. Poussot-Vassal)

(1997); Ahmadian and Reichert (2001); Guardabassi and Savaresi (2001); Giua et al. (2004); Geurts et al. (2006); Savaresi et al. (2010); Unger et al. (2011); Do et al. (2011b) and references therein).

This paper aims at addressing the second mainstream, by providing a - hopefully - complete system dynamical analysis, and a picture of the research and performance evaluation of controlled semi-active suspension systems.

Moreover, the concept of semi-active suspensions can be applied over a wide range of other application domains: cabin in trucks or tractors, seat, trains, appliances (e.g. washing machines), architectural (buildings, bridges, etc.), bio-mechanical structures (e.g. artificial legs) etc. (see e.g. Caponetto et al. (2003); Giua et al. (2004); Geurts et al. (2006); Liao and Wang (2003); Spelta et al. (2009); Codeca et al. (2007); Chrzan and Carlson (2001); Choi et al. (2000); Deprez et al. (2005)).

\subsection{Paper contributions}

In a previous work of the authors (see Poussot-Vassal et al. (2010)) a methodology to evaluate the best performance trade-off, in term of comfort and road-holding, a semi-active suspension system can achieve, has been proposed. Based on this recent development, the main contribution of this paper is to provide a full analysis of the system and benchmark some of the most common dedicated vehicle semi-active suspension control law performances, both for the comfort and for the road-holding objectives. This work is carried out on the basis of the well known single-corner vehicle model including a semi-active suspension system (see Figure 1). In this paper structural limitation properties and performances of different control algorithms are then thoroughly evaluated trough dedicated 
frequency domain simulations and gathered into a simple but comprehensive criteria allowing for a fast picture of the methodological challenges and trade-off.

\subsection{Notations and structure}

The paper is divided as follows: Section 2 presents the semi-active suspension problem statement and classically involved models. It also introduces some specific and remarkable semi-active suspension properties and a performance metrics used to quantify the comfort and road-holding abilities of any suspension system (either passive, semi-active or fully active). Then, Section 3 plays a pivotal role between performance and control law evaluation. More specifically, based on results provided in Poussot-Vassal et al. (2010), an optimisation-based procedure, as rooted in the Hybrid MPC framework, to evaluate the optimal comfort / road-holding trade-off is presented. Then, in Section 4 and 5, in a down top complexity framework, classical control methodologies to achieve comfort and road-holding performances, respectively, are presented. Then, more sophisticated and advanced approaches are presented in Section 6. All the aforementioned control approaches are then numerically evaluated and benchmarked with respect to the optimal performances in Section 7, using a motorcycle benchmark. Finally, Section 8 concludes the paper, providing also a quick compendium of comments on sensors-actuators-damping technologies.

\section{Semi-active suspension problem statement}

\subsection{Single-corner nonlinear model}

The single-corner vehicle model is the basic model used for suspension analysis. It consists in double mass / spring / damper system describing the dynamics of the chassis and the centre of the wheel. The suspension system is modelled by a spring and a damping system, and the tire is often reduced to a spring element. Figure 1 illustrates this single-corner model, defined through relation (1).

$$
\left\{\begin{aligned}
M \ddot{z} & =-k\left(z-z_{t}-\Delta_{s}\right)-c\left(\dot{z}-\dot{z}_{t}\right)-M g \\
m \ddot{z}_{t} & =k\left(z-z_{t}-\Delta_{s}\right)+c\left(\dot{z}-\dot{z}_{t}\right) \\
& -k_{t}\left(z_{t}-z_{r}-\Delta_{t}\right)-m g \\
\dot{c} & =-\beta\left(c-c_{i n}\right) \\
z_{t}-z_{r} & <\Delta_{t}
\end{aligned}\right.
$$

where $z, z_{t}$, and $z_{r}$ are the vertical positions of the body, of the unsprung mass, and of the road profile, respectively. $M$ is the single-corner body mass; $m$ is the unsprung mass (tire, wheel, brake calliper, suspension links, etc.). $g$ is the gravitational constant. $k \in \mathbb{R}^{+}$and $k_{t} \in \mathbb{R}^{+}$are the stiffness of the suspension spring and of the tire, respectively; $\Delta_{s} \in \mathbb{R}^{+}$and $\Delta_{t} \in \mathbb{R}^{+}$are the length of the unloaded suspension spring and tire, respectively. $c \in \mathbb{R}^{+}$and $c_{\text {in }} \in \mathbb{R}^{+}$ are the actual and the requested damping coefficients of the controlled shock-absorber, respectively. The dampingcoefficient variation is ruled by a 1st-order dynamic, where $\beta \in \mathbb{R}^{+}$is the bandwidth. The actual damping coefficient $c$ always remains in that interval: $c_{\min } \leq c \leq c_{\max }$, where $c_{\text {min }} \in \mathbb{R}^{+}$and $c_{\text {max }} \in \mathbb{R}^{+}$are the shock-absorber technological limitations. This last inequality is also referred as the passivity-constraint of a semi-active suspension - guaranteeing that the actuator only dissipates energy (see e.g. Savaresi and Spelta (2009); Savaresi et al. (2010)).

\subsection{Equilibrium points}

Based on model (1), the system equilibrium point is simply derived as follows:

$$
\left\{\begin{array}{r}
-k\left(z^{e q}-z_{t}^{e q}-L\right)-M g=0 \\
k\left(z^{e q}-z_{t}^{e q}-L\right)-k_{t}\left(z_{t}^{e q}-z_{r}^{e q}-R_{t}\right)-m g=0
\end{array}\right.
$$

Consequently, the solution is simply given as,

$$
\left[\begin{array}{c}
z^{e q} \\
z_{t}^{e q}
\end{array}\right]=\left[\begin{array}{cc}
-k & k \\
k & -k-k_{t}
\end{array}\right]^{-1}\left[\begin{array}{c}
M g-k L \\
m g+k L-k_{t} R_{t}-k_{t} z_{r}^{e q}
\end{array}\right]
$$

Then, by choosing $z_{r}^{e q}=0$, the equilibrium point may be rewritten as:

$$
\left[\begin{array}{c}
z^{e q} \\
z_{t}^{e q}
\end{array}\right]=\left[\begin{array}{r}
L-\frac{M g}{k}+R_{t}-\frac{(M+m) g}{k_{t}} \\
R_{t}-\frac{(M+m) g}{k_{t}}
\end{array}\right]
$$

This equilibrium point will then be used to simplify the system model, in order to consider only the dynamical parts.

\subsection{Single-corner nonlinear dynamical model}

Around the equilibrium point (4), the following nonlinear dynamical model is thus commonly used:

$$
\left\{\begin{aligned}
M \ddot{z} & =-k\left(z-z_{t}\right)-c\left(\dot{z}-\dot{z}_{t}\right) \\
m \ddot{z}_{t} & =k\left(z-z_{t}\right)+c\left(\dot{z}-\dot{z}_{t}\right)-k_{t}\left(z_{t}-z_{r}\right) \\
\dot{c} & =\beta\left(c_{i n}-c\right)
\end{aligned}\right.
$$

Since the control signal $c_{i n} \in\left[\begin{array}{ll}c_{\min } & c_{\max }\end{array}\right]$ modifies the damping coefficient $c$, a state variable, model (5) is obviously nonlinear.

Remark 1. For numerical simulations, the following set of parameters (representing a motorcycle system) will be considered: $M=117 \mathrm{Kg} ; \mathrm{m}=30 \mathrm{Kg} ; k=26 \mathrm{kN} / \mathrm{m} ; k_{t}=$ $250 \mathrm{kN} / \mathrm{m} ; c_{\min }=900 \mathrm{Ns} / \mathrm{m} ; c_{\max }=4300 \mathrm{Ns} / \mathrm{m} ; \beta=$ $50.2 \pi \mathrm{rad} / \mathrm{s}$ and finally $T_{e}=1 \mathrm{~ms}$ (when model discretized).

Remark 2. When a passive uncontrolled suspension is considered, (5) is reduced to a 4th-order linear system (by simply setting $\dot{c}=0$ and $c=$ constant - e.g. nominal damping). 


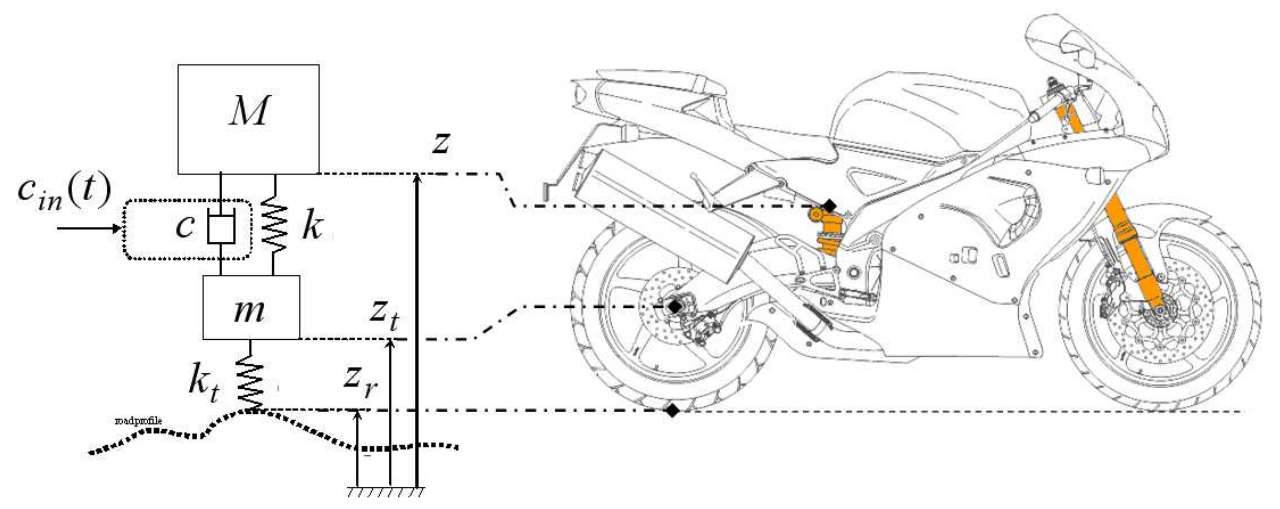

Figure 1: Single-corner vehicle model.

\subsection{Single-corner linear-like dynamical model}

In order to apply linear control techniques, it is possible to define a linear-like semi-active suspension model as follows:

$$
\left\{\begin{aligned}
M \ddot{z} & =-k\left(z-z_{t}\right)-c_{0}\left(\dot{z}-\dot{z}_{t}\right)-F_{d} \\
m \ddot{z}_{t} & =k\left(z-z_{t}\right)+c_{0}\left(\dot{z}-\dot{z}_{t}\right)-k_{t}\left(z_{t}-z_{r}\right)+F_{d} \\
\dot{F}_{d} & =-\beta\left(F_{d}-u\right)
\end{aligned}\right.
$$

With reference to models (1) and (5), the linearised model (6) includes symbols with the following meaning: $c_{0}$ denotes the nominal damping (which can be used as a design parameter when synthesizing the controller); $F_{d}$ is an additional damping force commanded by the control variable $u$, according to a 1 st order actuation dynamic.

In order to be fully equivalent to (1) and (5), the control signal $u$ should respect the passivity-constraint. In models (1) and (5) this constraint is described by $c_{\text {min }} \leq c_{i n} \leq$ $c_{\max }$. It is straightforward to see that in model (6) this constraint is recast as follows:

$$
\left\{u, \dot{z}-\dot{z}_{t}\right\} \in \mathcal{D}\left(c_{\min }, c_{\max }, c_{0}\right) \subseteq \mathbb{R}^{2}
$$

where the dissipative $\mathcal{D}\left(c_{\min }, c_{\max }, c_{0}\right)$ set is defined as follows (see also Figure 2):

$$
\left\{\begin{array}{c}
\forall(U, V) \in \mathbb{R} \times \mathbb{R} \mid \\
\left(U-\left(c_{\max }-c_{0}\right) V\right)\left(\left(c_{\min }-c_{0}\right) V-U\right) \geq 0
\end{array}\right\}
$$
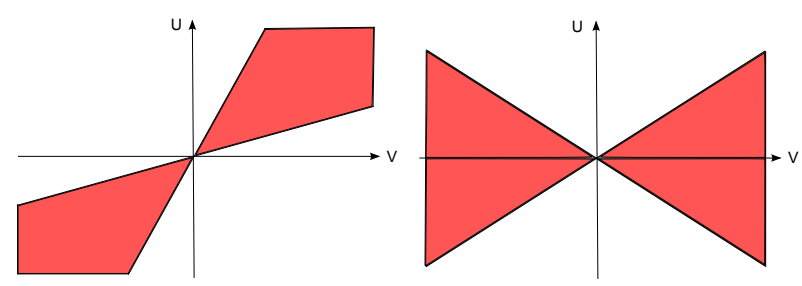

Figure 2: Illustration of the dissipative $\mathcal{D}\left(c_{\min }, c_{\max }, c_{0}\right)$ set as a function of $c_{0}$. Left: $c_{0}=0$, right: $c_{0}=\frac{c_{\min }+c_{\max }}{2}$.
Remark 3. Note that in formulation (6) of the singlecorner model, the system with no control $(u=0)$ is damped thanks to $c_{0}$ (hence stable and damped). This remark is practically important when numerical-based control synthesis methods are considered (e.g. LMI-based, $M P C, \ldots$ ).

\subsection{Invariance properties of the passive (uncontrolled) single- corner model}

Now, based on the dynamical model formulation (5), let define some specific transfer functions, from which remarkable properties can be derived. The following transfer functions are thus described (where $s=j \omega$ stands for the Laplace variable and $\dot{c}=0)$ :

- $F_{z}(s)$ and $F_{\ddot{z}}(s)$, the transfer function from the road vertical disturbance $Z_{r}(s)$ to the chassis displacement $Z(s)$ and acceleration $s^{2} Z(s)$ are defined as, respectively:

$$
\begin{aligned}
& F_{z}(s)=\frac{\left(c k_{t}\right) s+k_{t} k}{(M m) s^{4}+(c m+c M) s^{3}+} \\
& F_{\ddot{z}(s)}=s^{2} F_{z}(s)
\end{aligned}
$$

These transfer functions are usually related to comfort specifications. Then it is interesting to note that:

- $F_{z}(s)$ has a unitary static gain (the chassis follows the road movements) and tends to zero with a slope of $-60 \mathrm{~dB} / \operatorname{dec}$ as $s=j \omega$ increases.

- $F_{\ddot{z}}(s)$ has null static gain and tends to zero with a slope of $-20 \mathrm{~dB} / \operatorname{dec}$ as $s=j \omega$ increases.

- $F_{z_{t}}(s), F_{z-z_{t}}(s)$ and $F_{z_{t}-z_{r}}(s)$, the transfer from the road vertical disturbance $Z_{r}(s)$ to the wheel displacement $Z_{t}(s)$, the suspension deflection $Z_{z_{d e f}}=Z(s)-$ $Z_{t}(s)$ and the tire deflection $Z_{z_{d e f_{t}}}=Z_{t}(s)-Z_{r}(s)$ 
are defined as, respectively:

$$
\begin{aligned}
F_{z_{t}}(s)= & \frac{\left(M k_{t}\right) s^{2}+\left(c k_{t}\right) s+k_{t} k}{(M m) s^{4}+(c m+c M) s^{3}+} \\
& \left(M k+m k+M k_{t}\right) s^{2}+\left(c k_{t}\right) s+ \\
F_{z_{\text {def }}}(s)= & F_{z}(s)-F_{z_{t}}(s) \\
F_{z_{\text {deft }}}(s)= & F_{z_{t}}(s)-1
\end{aligned}
$$

These transfers are usually related to road-holding and suspension limitation specifications. Then it is interesting to note that:

- $F_{z_{t}}(s)$ has a unitary static gain and tends to zero with a slope of $-40 \mathrm{~dB} / \mathrm{dec}$ as $s=j \omega$ increases.

$-F_{z_{\text {def }}}(s)$ has null static gain and tends to zero with a slope of $-20 \mathrm{~dB} / \mathrm{dec}$ as $s=j \omega$ increases.

- $F_{z_{\text {deft }}}(s)$ has null static gain and tends to unitary gain as $s=j \omega$ increases.

Among these transfer, the system exhibits some invariant points (or invariant behaviours) with respect to the damping coefficient $c$. They are referred to as invariant since they characterize specific points in the frequency domain which cannot be modified with a given passive suspension. The interested reader may also refer to Sammier et al. (2003).

Before introducing the invariant points of interest for the passive single-corner model, let first define an invariant behaviour as follows:

Definition $1(F(j \omega, c)$-Invariant behavior). Let $F(j \omega, c)$ be a transfer function depending in a parameter $c \in \mathbb{R}$, where $\omega \in \Omega \subseteq \mathbb{R}^{+}$. Then, the transfer function $F(j \omega, c)$ has an invariant point (or invariant behaviour) with respect to the c parameter, iff. $\exists \eta \in \mathbb{R}^{+}$and $\omega_{0} \in \Omega$ such that $\forall c \in \mathbb{R}$,

$$
|F(j \omega, c)|_{\omega=\omega_{0}}=\eta
$$

Based on Definition 1, in the following properties 1, 2 and 3 the invariant points of the transfer functions $F_{z}(s)$, $F_{z_{\text {def }}}(s)$ and $F_{z_{\text {deft }}}(s)$ are given. Note that these invariant points are of particular interest for the semi-active application.

Property 1 ( $F_{z}(j \omega, c)$-Invariant points). The transfer $F_{z}(j \omega)$ related to the quarter car model, as given in (6), has four invariant points in $\omega \in \mathbb{R}^{+}$, defined as follows:

$$
\left\{\begin{aligned}
\omega_{1} & =0 \\
\omega_{2} & =\frac{1}{m M \sqrt{2}} \sqrt{m M\left(M k_{t}+2 M k+2 m k-\alpha_{z}\right)} \\
\omega_{3} & =\sqrt{\frac{k_{t}}{m}} \\
\omega_{4} & =\frac{1}{m M \sqrt{2}} \sqrt{m M\left(M k_{t}+2 M k+2 m k+\alpha_{z}\right)}
\end{aligned}\right.
$$

where,

$$
\alpha_{z}=\sqrt{\begin{array}{l}
4 m^{2} k^{2}-4 m k M k_{t}+8 M k^{2} m+ \\
M^{2} k_{t}^{2}+4 M^{2} k k_{t}+4 M^{2} k^{2}
\end{array}}
$$

Property 2 ( $F_{z_{\text {deft }}}(j \omega, c)$-Invariant points). The transfer $F_{z_{\text {deft }}}(j \omega)$ related to the quarter car model, as given in (6), has three invariant points in $\omega \in \mathbb{R}^{+}$, defined as follows:

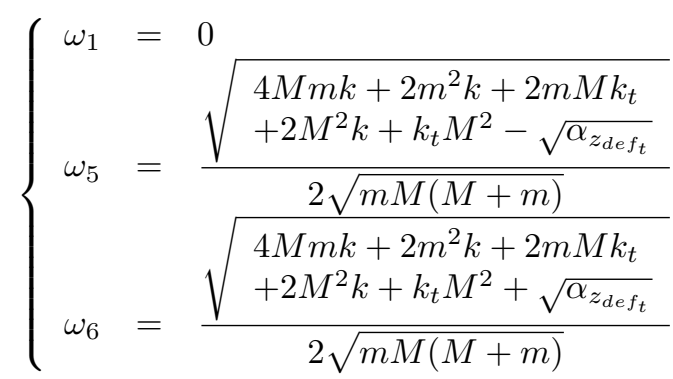

where,

$$
\begin{aligned}
\alpha_{z_{\text {deft }}} & =4 m^{4} k^{2}+4 M^{4} k^{2}+k_{t}^{2} M^{4} \\
& -12 M^{2} m^{2} k k_{t}-8 m^{3} k M k_{t}+24 M^{2} m^{2} k^{2} \\
& +16 M m^{3} k^{2}+16 M^{3} m k^{2}+4 m^{2} M^{2} k_{t}^{2} \\
& +4 m M^{3} k_{t}^{2}+4 M^{4} k k_{t}
\end{aligned}
$$

Property 3 ( $F_{z_{\text {def }}}(j \omega, c)$-Invariant points). The transfer $F_{z_{\text {def }}}(j \omega)$ related to the quarter car model, as given in (6), has two invariant points in $\omega \in \mathbb{R}^{+}$, defined as follows:

$$
\left\{\begin{aligned}
\omega_{1} & =0 \\
\omega_{7} & =\sqrt{\frac{k_{t}}{M+m}}
\end{aligned}\right.
$$

Proof 1. Proofs are provided in Chapter 3 of Savaresi et al. (2010).

Remark 4. Additionally, attentive reader should notice that the invariant points in $\omega_{1}=0, \omega_{3}=\sqrt{\frac{k_{t}}{m}}$ and $\omega_{7}=$ $\sqrt{\frac{k_{t}}{M+m}}$ are also independent from the $k$ (stiffness) parameter, which practically means that whatever the designed suspension (either passive, semi-active or even active), this point is not modified, i.e. these behaviours are also purely independent from both the spring and damping suspension forces Moreau (1995); Oustaloup et al. (1996).

These properties have to be kept in mind during the suspension control design step.

\subsection{Performance indexes definition}

Since the paper aims at evaluating the trade-off of the semi-active suspension laws in terms of comfort and road-holding, the performance metric proposed in PoussotVassal et al. $(2010,2011)$ is used here. This criteria focuses on two specific signals, representing either the comfort or the road-holding performance (for further detail, refer to Hrovat (1997); Kiencke and Nielsen (2000) and book of the authors Savaresi et al. (2010)), namely: 
- The vertical chassis acceleration $\ddot{z}$ (or displacement $z$ ) response to road disturbances $z_{r}$ (i.e. $F_{z}(s)$ or $F_{\ddot{z}}(s)$ transfer), between 0 and $20 \mathrm{~Hz}$, representing the acceleration felt by the driver, i.e. the comfort specification.

- The vertical wheel deflection $\left(z_{t}-z_{r}\right)$ response to road disturbances $z_{r}$ (i.e. $F_{z_{\text {deft }}}(s)$ transfer), between 0 and $30 \mathrm{~Hz}$, representing the ability of the wheel to stay in contact with the road, i.e. the roadholding specification.

The common objective is then to minimize either the transfer from $z_{r}$ to $\ddot{z}$ - identically $z$ - (comfort) or the transfer $z_{r}$ to $\left(z_{t}-z_{r}\right)$ (road-holding) or a combination of these two transfer over the considered frequency range. Since the applied control law may be nonlinear these transfer will be evaluated thanks to their nonlinear frequency response (FR), computed by mean of Algorithm 1. More specifically, to compute the approximate Frequency Response of $F_{z}(f)$ - comfort characteristic - and $F_{z_{\text {def }}}(f)$ - road-holding characteristic - of a (controlled) nonlinear suspension systems the following procedure is applied:

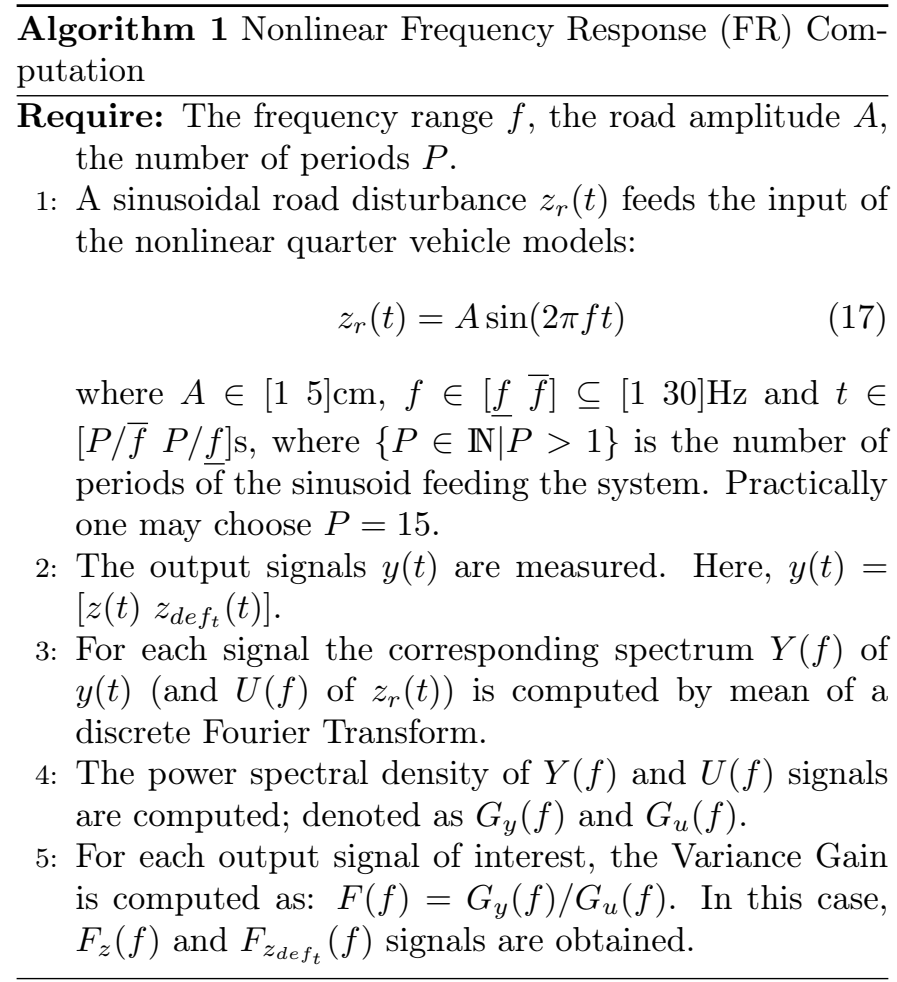

Remark 5. Note that the above procedure has much in common with the concept of describing function. Further for linear systems this corresponds to the numerical computation of the exact frequency response.

Remark 6. When applied to linear systems, the FR computed by Algorithm 1 recovers the classical Bode diagram.

Now, based on the FR computation, let define the performance metrics as follows:
Definition 2 (Performance metrics). Given $F_{z}(f)$ and $F_{z_{\text {deft }}}(f)$ and $F_{z}^{n o m}(f)$ and $F_{z_{\text {def }} \text { nom }}(f)$ as computed in Algorithm 1, the comfort and road-holding criteria are respectively defined as:

- $J_{c}$, Comfort criteria:

$$
J_{c}=\frac{\mathcal{C}\left(F_{z}(f), 0,20\right)}{\mathcal{C}\left(F_{z}^{n o m}(f), 0,20\right)}
$$

- $J_{r h}$, Road-holding criteria:

$$
J_{r h}=\frac{\mathcal{C}\left(F_{z_{\text {def }}}(f), 0,30\right)}{\mathcal{C}\left(F_{z_{\text {def }}}^{\text {nom }}(f), 0,30\right)}
$$

where $F_{z}(f)$ and $F_{z_{\text {def }}}(f)$ are the frequency response gains of the controlled suspension which is to be analyzed, while $F_{z}^{n o m}(f)$ and $F_{z_{\text {def }}}^{\text {nom }}(f)$ are the frequency response gains of the passive uncontrolled reference suspension system with a nominal damping of $1500 \mathrm{Nm} / \mathrm{s}$ (i.e. model (5) with $c=1500$ and $\left.c_{\text {in }}=1500\right)$. And where, the function $\mathcal{C}$ : $\mathbb{R} \times \mathbb{R} \times \mathbb{R} \rightarrow \mathbb{R}$, is given as:

$$
\mathcal{C}(x, \underline{f}, \bar{f})=\int_{\underline{f}}^{\bar{f}}|x(f)|^{2} d f
$$

where $x(f)$ represents the frequency dependent signal of interest, and $f$ and $\bar{f}$ represent the lower and higher frequency of interval limits of interest, respectively.

This criteria will now on be used to evaluate the performances of any linear or nonlinear controlled semi-active suspension system.

\section{Optimal semi-active performance computation}

In view of benchmarking the performances of different dedicated semi-active suspension control algorithms, it is very convenient to evaluate the best performances such a system can achieved, if optimally controlled.

Due to the complexity and the nonlinear phenomena composing the semi-active suspension systems, these optimal performances cannot be analytically calculated but approximated through a numerical optimisation approach, grounded on Model Predictive Control (MPC, see e.g. Bemporad et al. (2003b,a)). Indeed, since the semi-active quarter-car model presents actuator limitations which may be viewed as variable saturations, the method consists in describing a nonlinear optimisation problem with the following elements (indeed the problem will be defined as a mixed-integer optimisation one, to take the advantage to recent optimisation tools, namely - GLPK (2009); Lofberg (2004)):

- A cost function, representing the performance objectives, either comfort or road-holding, to be minimized (described in Section 3.1). 
- A single corner model (given in discrete-time), which represents the dynamical equality constraints of the optimisation problem (described in Section 3.2).

- A set of logical control inequality constraints guaranteeing the Section passivity-constraint of the actuator. These constraints are specific for the semi-active application and they will be described with binary variables in the optimisation problem (see Section $3.3)$.

Additionally, since the aim of this section is to evaluate the optimal theoretical performances a semi-active suspension system can achieve, the following assumptions are made:

- The measure of the road disturbance $z_{r}$ is considered as known for a given time horizon consisting of $N$ samples, namely, $Z_{r}(k)=\left[z_{r}(k) z_{r}\left(k T_{e}\right) \ldots z_{r}(k(N-\right.$ 1) $\left.\left.T_{e}\right)\right]^{T}$, is known.

- The variables $z, z_{t}$ and $z_{r}$ are measurable.

- The system model is perfectly known.

On Figure 3, the general iterative optimisation scheme to compute the optimal comfort and road-holding bounds is shown, gathering the previous objectives and hypotheses.

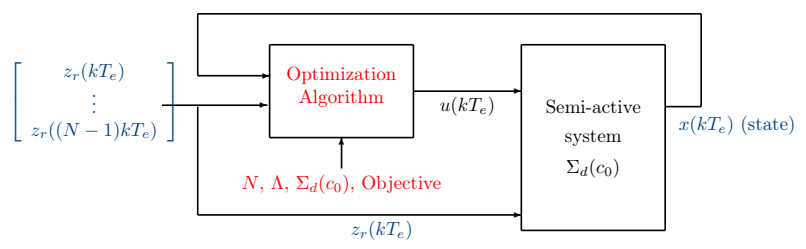

Figure 3: Computation scheme of the semi-active suspension optimal performance.

With reference to Figure 3 the "Optimisation Algorithm" takes as input the state measure $x\left(k T_{e}\right)$ and the present and future of road disturbance collected in vector $Z_{r}(k)$. In the following, cost functions, equality and inequality constraints are described, and then, finally, the complete optimisation problem is given in Section 3.4.

\subsection{Cost (objective) functions}

As described in Definition 2, the aim of a suspension system in a vehicle is to filter the road disturbances to the body (comfort perspective), without deteriorating the road-tire contact forces (road-holding perspective). To properly define these objective, let redefine the following cost functions (defined through $\mathcal{L}_{2}$ metrics):

- The comfort cost function:

$$
J_{c}(N)=\sum_{k=0}^{N-1}(z(k))^{2}
$$

which measures the vertical acceleration of the suspended mass $M$ over $N$ samples.
- The road-holding cost function:

$$
J_{r h}(N)=\sum_{k=0}^{N-1}\left(z_{t}(k)-z_{r}(k)\right)^{2}
$$

which measures the vertical tire deflection $z_{t}(k)-$ $z_{r}(k)$ over $N$ samples.

Remark 7. Note that these time domain objectives are equivalent to the one defined in (18) and (19).

\subsection{System equality constraints}

The equality constraints of the optimisation problem are gathered in the dynamical system definition (6), recalled here in its LTI form as,

$$
\Sigma_{c}\left(c_{0}\right): \dot{X}=A\left(c_{0}\right) X+B W
$$

where $c_{0}=\left(c_{\min }+c_{\max }\right) / 2$. Then, in order to describe the optimisation problem, model (23) is defined in the discretetime domain (through backward Euler method with a sampling time $\left.T_{e}\right)$. The resulting discrete-time model $\Sigma_{d}\left(c_{0}\right)$ is given by:

$$
\Sigma_{d}\left(c_{0}\right): X(k+1)=\left(I+A\left(c_{0}\right)\right) T_{e} X(k)+B T_{e} W(k)
$$

where,

$$
\begin{aligned}
X(k) & =\left[z(k+1) z(k) z_{t}(k+1) z_{t}(k) F_{d}(k)\right]^{T} \\
W(k) & =\left[z_{r}(k) u(k)\right]^{T}
\end{aligned}
$$

and where $A \in \mathbb{R}^{5 \times 5}$ and $B \in \mathbb{R}^{5 \times 2}$ are the dynamic and the input matrix of the system, respectively.

\subsection{Actuator inequality constraints}

Similarly, the optimisation inequality constraints are contained in the passivity-constraint definition. These (logical) inequality constraints aim at guaranteeing the fact that the control signal lies in $\mathcal{D}\left(c_{\min }, c_{\max }, c_{0}\right)$, the dissipative domain.

Let define $\Lambda$, the set of logic constraints, containing binary variables, ensuring that the control signal $(u(k))$ lies in domain $\mathcal{D}\left(c_{\min }, c_{\max }, c_{0}\right)$, as:

$$
\begin{array}{r}
\text { if } z(k+1)-z_{t}(k+1) \geq 0, \Lambda: \\
\left\{\begin{array}{l}
u(k) \geq\left(c_{\text {min }}-c_{0}\right)\left(z(k+1)-z_{t}(k+1)\right) \\
u(k) \leq\left(c_{\max }-c_{0}\right)\left(z(k+1)-z_{t}(k+1)\right)
\end{array}\right. \\
\left\{\begin{array}{l}
u(k) \leq\left(c_{\min }-c_{0}\right)\left(z(k+1)-z_{t}(k+1)\right) \\
u(k) \geq\left(c_{\max }-c_{0}\right)\left(z(k+1)-z_{t}(k+1)\right)
\end{array}\right.
\end{array}
$$

where $\dot{z}-\dot{z}_{t}$, the suspension deflection velocity, is defined as a binary variable, allowing to "choose" the active inequality constraint. $\left(c_{\min }-c_{0}\right)\left(\right.$ resp. $\left.\left(c_{\max }-c_{0}\right)\right)$ is the new minimal (resp. maximal) allowable damping ratio of the considered nominally damped discrete-time quartercar model. 
Behind this constraint definition, it clearly appears that the control signal is dependent on the state value, and especially, on the state sign. Therefore, the $\Lambda$ constraints involve binary variables. This peculiarity makes the problem non trivial; as a matter of fact, the optimisation problem became a mixed-integer optimisation problem.

\subsection{Optimisation problem definition}

Following the previous definitions, and under Figure 3 perspective, the following MPC optimisation problem may be defined:

$$
\begin{aligned}
& J_{i}^{*}(N)=\min _{u}(k) J_{i}(N) \\
& \text { s.t. }\left\{\begin{array}{lll}
X(k+1) & = & (24) \\
\Lambda & = & (26)
\end{array}\right.
\end{aligned}
$$

where $J_{i}, i=\{c, r h\}$, is the criteria to be minimized over the time horizon consisting of $N$ samples, $\Lambda$ is the set of inequality logical constraints and $X(k+1)$ are the dynamical equality constraints initialized by $X(k)$, the state measure at the given iteration. The problem may be solved either for the comfort index (21) or for the road-holding index (22).

Since this problem is linear and involves logical constraints, it can be iteratively solved by using the YALMIP parser Lofberg (2004) together with GLPK general optimisation solver GLPK (2009). In conclusion, note that the optimisation problem (27) depends on a design parameter corresponding to the time horizon $N$.

\subsection{Analysis of the comfort optimal performances}

In Figure 4, the results of the FR, obtained by mean of Algorithm 1 - with numerical values of Remark 1 - for the comfort optimisation are reported. For benchmarking, the results are compared with the suspension performances with minimum or maximum level of damping dashed lines). Figure 4 reports also the results sensitivity to the optimisation horizon parameter $N$.

In terms of comfort (Figure 4 - left) there exist two resonances (clearly visible for low damping). A first body resonance around $2 \mathrm{~Hz}$ and a wheel resonance around $13 \mathrm{~Hz}$. These two resonances are shown also in the road-holding approximate FR (Figure 4 - right).

- The comfort passive trade-off between minimum damping $\left(c_{\min }\right)$ and maximum damping $\left(c_{\max }\right)$ is obvious (Figure 4 - left). At low frequency a high damped suspension provides a good damping of the body resonance, but a bad filter of mid and high frequencies. On the other hand a low damping ensures a good filtering but a badly damped body resonance.

- The road-holding passive trade-off has an opposite flavour (Figure 4 - right). The high damping guarantees the best results in terms of tire deflection around the body and the wheel resonance. However at mid frequencies a low damped suspension provides better results. Also in this situation any passive setting represents a compromise between a over and under damped suspension.

- The optimal comfort response is able to outperform the passive settings at every frequency (Figure 4 left). Interestingly enough it seems to inherit the best behaviour of $c_{\text {min }}$ at mid-high frequencies, and of $c_{\max }$ at low frequencies. It is worth noticing also that the optimal control of the damper is able to remove the limitation of the damping invariant point.

- The optimal comfort response provides performances comparable with a low damped suspension in terms of road-holding (Figure 4 - right). Note that, in these terms, the best of comfort is achievable without a deterioration of the road-holding performances (apart from the wheel resonance, where a little degradation occurs).

- The sensitivity analysis of $N$ is also reported in Figure 4. Note that, as excepted, the larger the better. In particular the sensitivity seems to be more critical around the wheel resonance, where the time horizon turns to be comparable to the suspension dynamics.

- In high frequencies (above $10 \mathrm{~Hz}$ ), the FR of $F_{z}$ appears to be not so well attenuated, and chattering. This is mainly due to the FR numerical computation. Anyway, it does not affect the analysis since gains are very small.

\subsection{Analysis of the roand-holding optimal performances}

The road-holding counterpart of this analysis is reported in Figure 5, which reports the results of optimisation problem (27) for the road-holding cost function (22). From Figure 5 some considerations can be drawn:

- The road-holding optimal response is able to remove the passive trade-off almost completely. It behaves at a mid damped suspension at low frequency, like a low damped suspension at mid frequencies and like a over-damped suspension around the wheel resonance.

- The optimal road-holding control provides the best results in terms of road-holding without a degradation of the performances in terms of comfort. Note that the best road-holding performances are comparable with a low damped suspension in terms of comfort.

- The sensitivity analysis confirms the above results of the comfort optimisation.

- Similarly to the above comfort case, in very low frequencies, the optimisation does not seems to optimally operate, but since it concerns very low amplitude, the FR of $F_{z_{\text {def }}}$ does not significantly affect the results. 

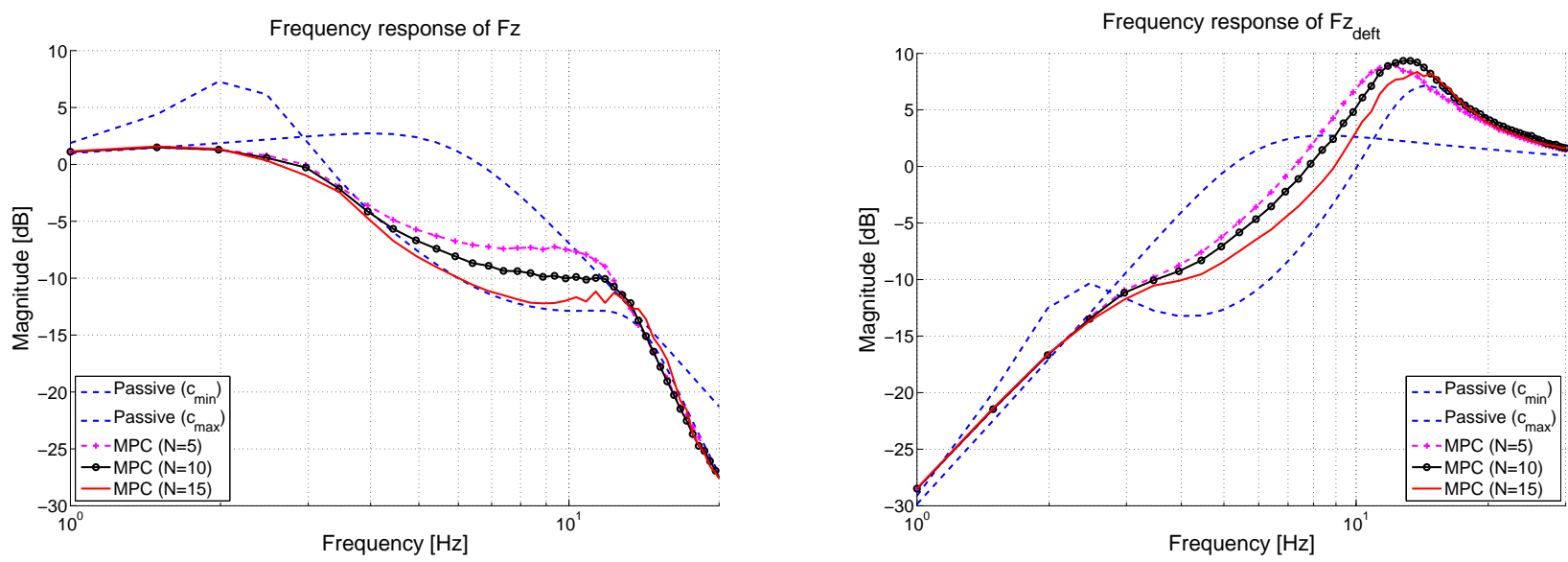

Figure 4: Results of the comfort-oriented optimisation (i.e. cost function $J_{c}$ ) with varying prediction horizon $N$. Left: approximate FR from the road vertical acceleration to the body vertical acceleration. Right: approximate FR from the road profile to the tire deflection.
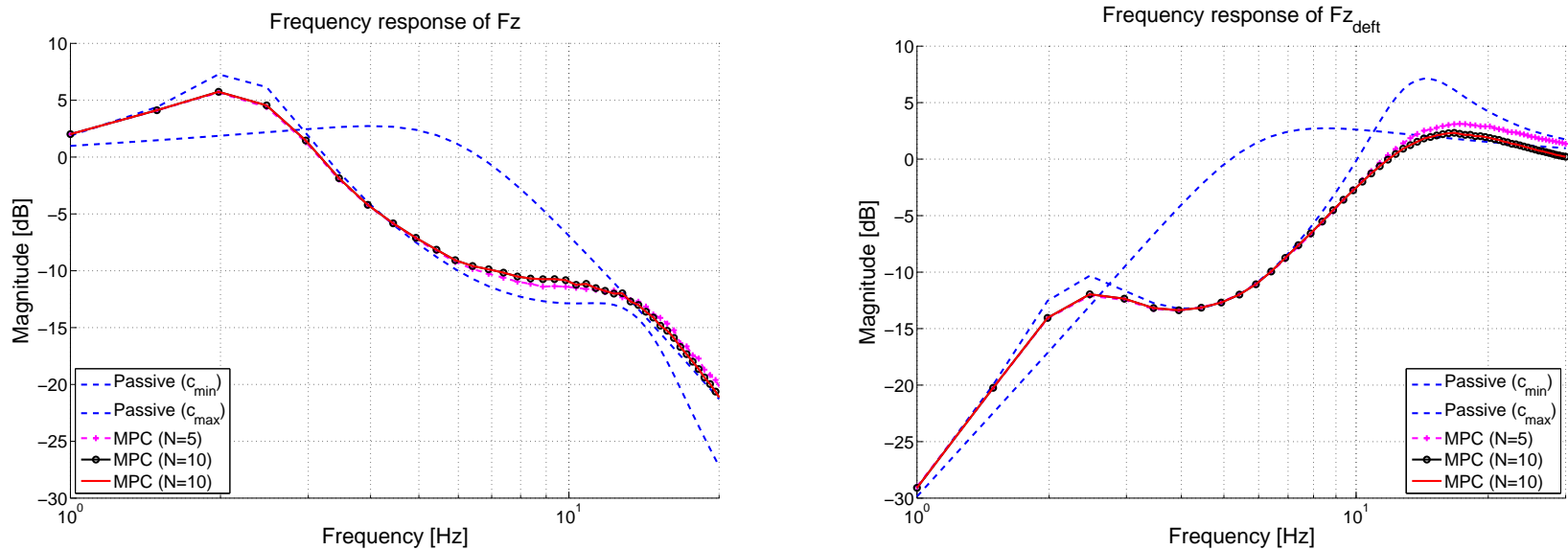

Figure 5: Results of the road-holding-oriented optimisation (i.e. cost function $J_{r h}$ ) with varying prediction horizon $N$. Left: approximate FR from the road vertical acceleration to the body vertical acceleration. Right: approximate FR from the road profile to the tire deflection.

Concluding the analysis, note that there exists a compromise between the best road-holding and the best comfort, which cannot be optimized simultaneously.

\subsection{Performance indexes and comfort/road-holding trade- off}

With reference to performance indexes given in equations (18) and (19), the numerical computation of these indexes are reported in Figure 6. These results confirm, concisely, the above analysis.

In the continuity, to evaluate the trade-off between the comfort and the road-holding optimal bound the following cost function is herein introduced (with $\alpha \in\left[\begin{array}{ll}0 & 1\end{array}\right]$ ):

$$
J_{\alpha}(N)=\alpha J_{c}(N)+(1-\alpha) J_{h}(N)
$$

Problem (27) is then solved for the optimisation index (28). Note that index (28) is a convex combination of the comfort index (21) and the road-holding index (22). In Figure 7 the optimisation task is solved for several values of $\alpha$ and the results are depicted in the comfort-road-holding plane. For comparison, also a representation of the passive trade-off is depicted (i.e. with varying frozen damping value).

Note that, for any value of the convex parameter $\alpha$ an optimally controlled suspension outperforms a passive suspension for any fixed damping value in terms of the performance index (28). This provides an interesting picture of the potential benefits guarantee by the use of a semi-active suspension. Figure 7 also highlights how any control of the damping parameter $c$ may be viewed as a compromise between the best road-holding and the best comfort.

\section{Comfort-oriented semi-active suspension control}

This section focusses on the main comfort-oriented dedicated semi-active suspension control strategies. This section gathers, in an increasing complexity order, the main 


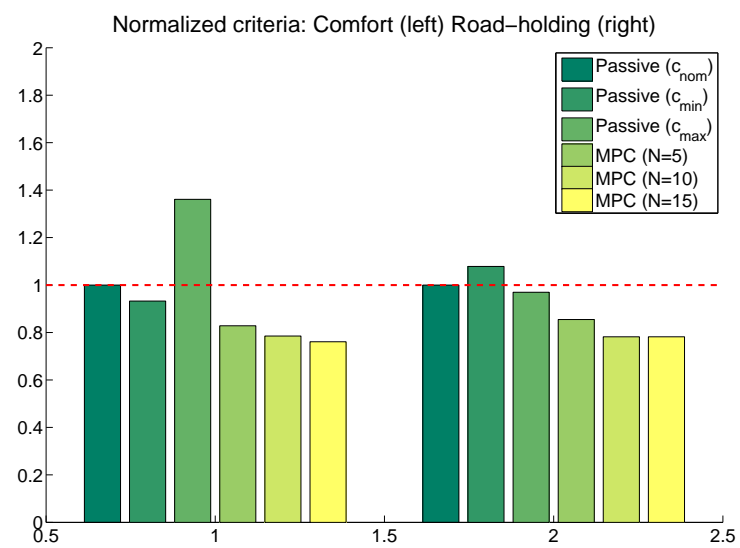

Figure 6: Performance criteria (normalized with respect to performance obtained with nominal damping $c_{0}=c_{n o m}$ ). Optimal performance with respect to the prediction horizon $N$, compared to the passive settings. Left: comfort optimisation $(i=c)$. Right: roadholding optimisation $(i=r h)$.

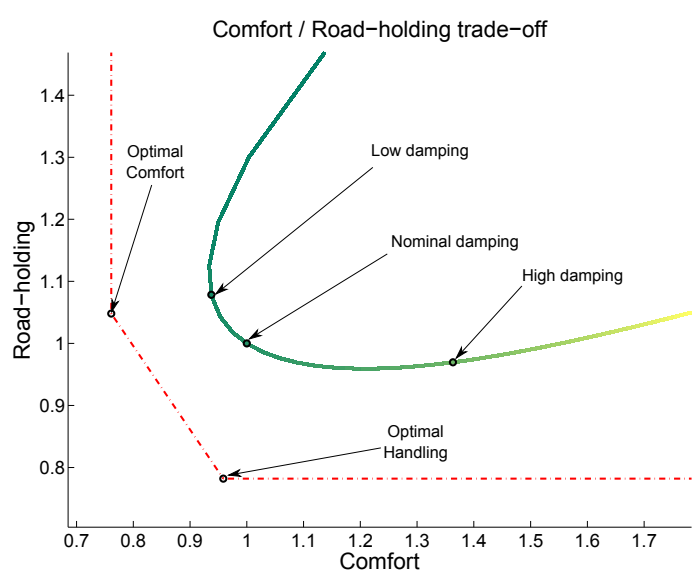

Figure 7: Comfort-road-holding trade-off $\left(\left\{J_{z}, J_{z_{\text {def }}}\right\}\right)$ for a passive suspension, with damping value $c \in\left[\begin{array}{ll}c_{\min } & c_{\max }\end{array}\right]$ (solid line with varying color) and optimal comfort / road-holding bounds, with $\alpha \in$ $\left[\begin{array}{ll}0 & 1\end{array}\right]$ (red dash dotted). semi-active control laws for comfort objective.

\subsection{Skyhook two-state damper control (SH-2)}

The two-state Skyhook control is an on/off strategy that switches between high and low damping coefficients in order to achieve body comfort specifications. This control law is recalled as follows.

Proposition 1 (SH-2 states control). Given system (5), the $S H-2$ law is defined as:

$$
c_{i n}= \begin{cases}c_{\text {min }} & \text { if } \dot{z} \dot{z}_{\text {def }} \leq 0 \\ c_{\text {max }} & \text { if } \dot{z} \dot{z}_{\text {def }}>0\end{cases}
$$

Basically, this control law consists in a switching controller which deactivates the controlled damper when the body speed and suspension deflection speed have opposite signs. The controlled damper technology only needs to have two damping coefficient states. This control strategy presents the advantage to be simple but requires two sensors.

Many studies have concerned the Skyhook control strategy since it represents a simple but efficient way to achieve good comfort requirement (see e.g. Simon (2001); Ahmadian et al. (2004)). Some extended versions of the Skyhook control have been also developed, such as the adaptive one in Song et al. (2007) or the gain-scheduled one in Hong et al. (2002).

\subsection{Skyhook linear approximation damper control (SH-L)}

An improved version of Skyhook control has been used to handle variable damping, either with discrete damping coefficients, or with continuously variable damper, as illustrated in Sohn et al. (2000). The linear approximation of the Skyhook control algorithm, adapted to semi-active suspension actuators, is given as:

Proposition 2 (SH-L). Given system (5), the SH-L law is defined as:

$c_{i n}= \begin{cases}c_{\text {min }} & \text { if } \dot{z} \dot{z}_{\text {def }} \leq 0 \\ \operatorname{sat}\left(\frac{\alpha c_{\text {max }} \dot{z}_{\text {def }}+(1-\alpha) c_{\max } \dot{z}}{\dot{z}_{\text {def }}}\right) & \text { if } \dot{z} \dot{z}_{\text {def }}>0\end{cases}$

where $\alpha \in\left[\begin{array}{ll}0 & 1\end{array}\right]$ is a tuning parameter that modifies the closed-loop performances and sat is the saturation function, denoting that $c_{i n} \in\left[\begin{array}{ll}c_{\min } & c_{\max }\end{array}\right]$.

When $\alpha=1$, this control law is equivalent to the Skyhook two-state one. As the two-state control, the linear approximation consists in a switching controller which modifies the damping factor according to the body speed and suspension deflection speed. The innovation rely in the fact that, according to the second expression (when $\dot{z} \dot{z}_{\text {def }}>0$ ), such a control provides an infinite number of damping coefficients. As a matter of fact, this control law requires a continuously variable controlled damper (e.g. an MR dampers). From the computational point of view, this control law also requires two measurements and is simple to implement, but suffers of $\dot{z}_{\text {def }}$ zero crossing as well (which is practically complex to measure). 


\subsection{Acceleration Driven Damper control (ADD)}

The ADD control is a semi-active control law described in Savaresi et al. (2005), which consists in changing the damping factor using the acceleration knowledge.

Proposition 3 (ADD). Given system (5), the ADD law is defined as:

$$
c_{\text {in }}= \begin{cases}c_{\text {min }} & \text { if } \ddot{z} \dot{z}_{\text {def }} \leq 0 \\ c_{\text {max }} & \text { if } \ddot{z} \dot{z}_{\text {def }}>0\end{cases}
$$

This strategy shows to be optimal in the sense that it minimizes the vertical body acceleration when no road information is available. Since it requires the same number of sensors as the Skyhook two-state and the linear approximations control law, this control law is simple from the implementation point of view. Note that the control law is very similar to the two-state approximation of the Skyhook algorithm, with the difference that the switching law depends on the body acceleration $(\ddot{z})$, instead of the body speed (which is easier to practically measure). It is also to note that the ADD design is well adapted to comfort improvement but not to road-holding. Nevertheless, as the previous approach, the "switching dynamic" may influences the closed-loop performances, implying chattering effects.

\subsection{Power Driven Damper (PDD)}

In Morselli and Zanasi (2008), the authors propose a semi-active suspension control strategy using the port Hamiltonian techniques, that provide powerful tools for modelling mechanicals systems with dissipative components. Based on this observation, it is straightforward that this framework perfectly fits the semi-active suspension problem.

Proposition 4 (PDD). Given system (5), the PDD control approach is described by:

$$
c_{i n}= \begin{cases}c_{\min } & \text { if } k z_{\text {def }} \dot{z}_{\text {def }}+c_{\min } \dot{z}_{\text {def }} \geq 0 \\ c_{\max }+c_{\max } & \text { if } k z_{\text {def }} \dot{z}_{\text {def }}+c_{\max } \dot{z}_{\text {def }}<0 \\ \frac{c_{\min }}{2} & \text { if } z_{\text {def }} \neq 0 \text { and } \dot{z}_{\text {def }}=0 \\ -\frac{k z_{\text {def }}}{\dot{z}_{\text {def }}} & \text { otherwise }\end{cases}
$$

where $k$ is the stiffness of the considered suspension.

In Morselli and Zanasi (2008) (see also Figures 8, 11 and 12 ), the authors show that this strategy provides results comparable to those of the ADD control law, while avoiding the chattering effect of the damping control value. The additional cost is the need for the knowledge of the spring stiffness $k$ and a more complex rule.

\subsection{Mixed Skyhook-Acceleration Driven Damper (SH-ADD)}

The Mixed Skyhook-ADD rational mixes the best behaviour of $\mathrm{SH}$ and $\mathrm{ADD}$, without an increasing of either the computational effort or the hardware complexity. The key idea exploits a very simple but effective frequency range selector, which is able to distinguish the instantaneous dynamical behaviour of the suspension: in the case of low frequency dynamics the $\mathrm{SH}$ is selected, while the ADD is selected otherwise. The resulting control law is incredibly simple and requires the same apparatus as $\mathrm{SH}$ (see also Savaresi and Spelta (2007, 2009); Spelta et al. (2010)).

Proposition 5 (SH-ADD). Given system (5), the mixed $S H-A D D$ control approach is described by:

$c_{\text {in }}= \begin{cases}c_{\max } \text { if } \quad\left[\left(\ddot{z}^{2}-\alpha^{2} \dot{z}^{2}\right) \leq 0 \text { AND } \dot{z} \dot{z}_{\text {def }}>0\right] \\ \\ & {\left[\left(\ddot{z}^{2}-\alpha^{2} \dot{z}^{2}\right)>0 \text { AND } \dot{z} \dot{z}_{\text {def }}>0\right]} \\ & \text { otherwise }\end{cases}$

where $\alpha \in \mathbb{R}^{+}$is the tuning parameter allowing for frequency range selector, i.e. adjusts the "switch" between the $S H$ and the $A D D$.

The amount $\left(\ddot{z}^{2}-\alpha^{2} \dot{z}^{2}\right)$ hence can be considered as a simple "frequency-range selector". The parameter $\alpha$ represents the frequency limit between the low and the high frequency ranges, and it is the only tuning knob of the control strategy (33). Specifically the value of $\alpha$ is set at the cross-over frequency (in $\mathrm{rad} / \mathrm{s}$ ) between SH and ADD. For a standard motorcycle suspension it has to be selected around $19 \mathrm{rad} / \mathrm{s}(3 \mathrm{~Hz})$. A simplified version of this algorithm, employing one single sensor has also been developed, leading to very satisfactory results both in simulation and experimental benchmark (see Savaresi and Spelta (2009)).

\section{Road-holding oriented semi-active suspension con- trol}

Complementary to comfort-oriented control strategies, a very few studies have been devoted to the possible improvement of road-holding, using suspension actuators. Indeed, studies on Global Chassis Control (see e.g. PoussotVassal (2008)) have emphasized road-holding the suspension system may also improve vehicle handling performances when critical steering and braking situations are encountered, encouraging the community to reach this new objective.

\subsection{Ground-hook 2 states (GH-2)}

As a dual of the Skyhook case, the 2-states Groundhook control (see Valasek et al. (1998)) consists in a switching control law depending now on the sign of the product between the suspension deflection velocity $\dot{z}_{\text {def }}$ and the velocity of the unsprung mass $\dot{z}_{t}$, as: 
Proposition 6 (GH-2). Given system (5), the GH-2 control approach is:

$$
c_{i n}= \begin{cases}c_{\text {min }} & \text { if }-\dot{z}_{t} \dot{z}_{\text {def }} \leq 0 \\ c_{\text {max }} & \text { if }-\dot{z}_{t} \dot{z}_{\text {def }}>0\end{cases}
$$

This control has globally the same properties as the SH-2 one, but focussing around the unsprung mass.

\subsection{Ground-hook linear (GH-L)}

In this case, the semi-active damper allows to continuously change the damping coefficient, according to:

Proposition 7 (GH-L). Given system (5), the GH-L control approach is defined through:

$c_{i n}= \begin{cases}c_{\min } & \text { if }-\dot{z}_{t} \dot{z}_{\text {def }} \leq 0 \\ \operatorname{sat}\left(\frac{\alpha c_{\max } \dot{z}_{\text {def }}+(1-\alpha) c_{\max } \dot{z}_{t}}{\dot{z}_{\text {def }}}\right) & \text { if }-\dot{z}_{t} \dot{z}_{\text {def }}>0\end{cases}$

where $\alpha \in\left[\begin{array}{ll}0 & 1\end{array}\right]$ is a tuning parameter that modifies the closed-loop performances and sat is the saturation function, denoting that $c_{i n} \in\left[\begin{array}{ll}c_{\min } & c_{\max }\end{array}\right]$.

\section{Advanced semi-active suspension control}

Until now, the presented control approaches where completely dedicated to semi-active suspension systems and based on the nonlinear model (5). In this section the description of some of the main semi-active suspension control method is done, based on more classical (or usual) control tools, and relying on the linear-like model (6).

\subsection{Clipped approaches}

Many works have concerned the application of classical control methods (e.g. $\mathcal{H}_{\infty}, \mathcal{H}_{2}$, pole placement, disturbance rejection, optimal, active Skyhook ...). However, most of the results were obtained for active suspensions, as in Zin et al. (2008). When applied to semi-active dampers, the dissipative constraint of the damper is usually handled using a simple projection (i.e. saturation, as shown in Figure 2). Even if it is not always referred to as the "clipped approach", the latter is very widespread in control strategies for semi-active suspension (see e.g. Karnopp et al. (1974) and Margolis (1983)). In the control step, the force applied by the semi-active damper is then chosen to be as close as to the force required by the controller for a given suspension deflection speed and for the possible range of forces the damper can deliver. This simple strategy has been then applied in many cases (see e.g. Rossi and Lucente (2004); Du et al. (2005); Sammier et al. (2003); Sename and Dugard (2003)).

The question that arises is: is optimal the clippedoptimal? If not, how far is it from the real optimal one? How would look like the optimal semi-active one? Clipped approaches lead to unpredictable behaviours and ensure neither closed-loop internal stability nor performances any longer. As a matter of fact, active control applied on a semi-active damper results in a "synthesize and try" method.

To cope with this last drawback, some modern control techniques have been applied to the specific semi-active suspension problem.

\subsection{Hybrid MPC control approaches}

In Giorgetti et al. (2006), the authors introduce an hybrid model predictive optimal controller (using receding horizon). They solve an off-line optimization process which is a finite horizon optimal regulation problem s.t.:

$J^{*}(\xi, x(k))=\min _{\xi}\left[x^{T}(N) Q_{N} x(N)+\sum_{k=1}^{N-1} x^{T}(k) Q x(k)+y^{2}(k)\right]$

subject to,

$$
\left\{\begin{aligned}
x(k+1) & =A x(k)+B u(k) \\
y(k) & =C x(k)+D u(k) \\
0 & \leq u(k) \dot{z}_{\text {def }}(k) \\
|u(k)| & \leq \Xi
\end{aligned}\right.
$$

where $Q$ is a performance index and $Q_{N}$ is the final weight, as in the optimal control theory. Matrices $A, B, C$ and $D$ in (37) define the LTI single-corner model (24), $\Xi$ is the maximal force allowed by the considered controlled damper and $u(k) \dot{z}_{\text {def }}(k) \geq 0$ guarantees the passivity constraint. $\xi$ is a vector composed by the sequence of control signals (from 0 to $N-1$ ) to be applied, where, $N$ is the prediction horizon. Giorgetti et al. (2006) show that choosing $N=1$ leads to performances that are identical to those of the clipped-optimal approach, and by increasing $N$ (e.g. until 40), the performances can be significantly improved. The implemented control law does not involve any optimization procedure since the control algorithm provides a collection of affine gains over a polyhedral partition of the system states $x$ (e.g. Borrelli et al. (2003)). By the way, this approach exhibits notable drawbacks, such as high complexity and switching between control regions and requires a complete full-state measurement.

\subsection{LPV semi-active control}

In an other philosophy, the "LPV semi-active" control adjustment, introduced in Poussot-Vassal et al. (2008), is a robust semi-active suspension control design using a Linear Parameter Varying (LPV) approach. More specifically, the proposed semi-active suspension control strategy is designed so that it minimizes the $\mathcal{H}_{\infty}$ performance criteria while guaranteeing the dissipative constraint thanks to a specific parameter dependent structure and a scheduling strategy design. The "LPV semi-active" controller design is summarized in Algorithm 2 - for $\mathcal{H}_{\infty}$ performances objectives.

In this algorithm, $\rho$ is a parameter function of the type of semi-active actuator. It varies as a function of the deflection velocity $\left(\dot{z}-\dot{z}_{t}\right)$ and the required damping 


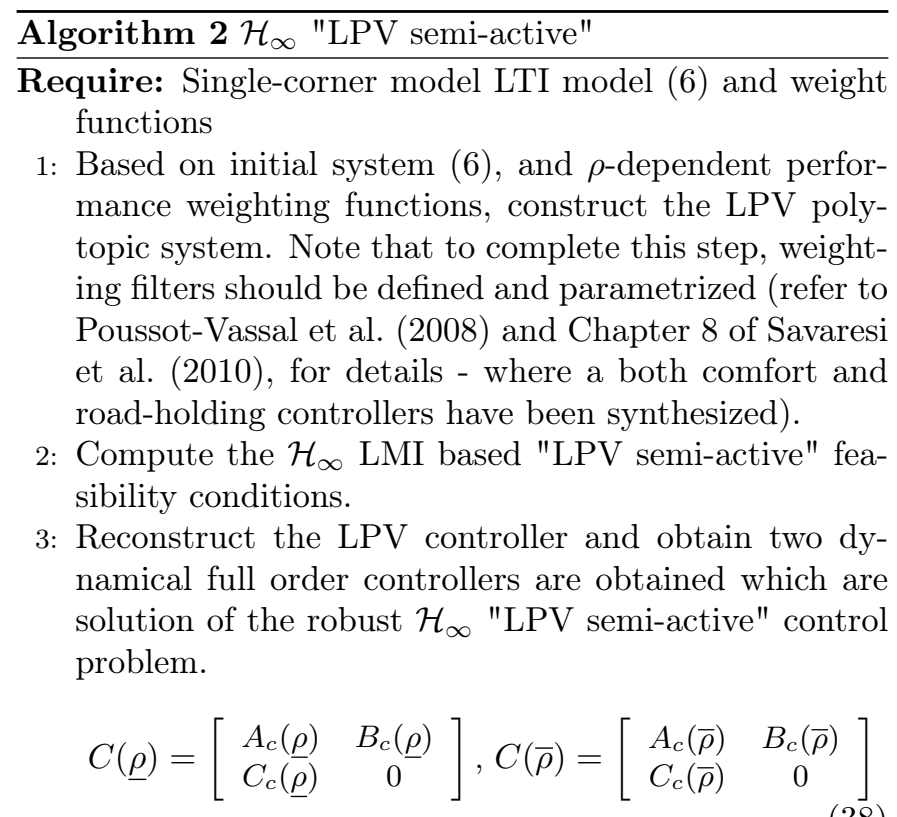

4: Apply control law (where $\rho$ is varying):

$$
u=\left(\frac{|\rho-\bar{\rho}|}{\bar{\rho}-\underline{\rho}} C(\underline{\rho})+\frac{|\rho-\underline{\rho}|}{\bar{\rho}-\underline{\rho}} C(\bar{\rho})\right) z_{d e f}
$$

Ensure: Close-loop internal stability and $\mathcal{H}_{\infty}$ performance level.

force (for more details refer to Poussot-Vassal et al. (2008); Savaresi et al. (2010)). The main interest of such an approach is that it presents a large flexibility concerning the performances and the type and number of involved sensors, as illustrated in Section 7. Additionally, it provides a robustness certificate thanks to the polytopic approach. The inherent counterpart of this flexibility is an important complexity in the design step. Extended versions of this approach have been recently presented in Do et al. (2010, 2011a), representing the damping actuator in an LPV form, and using control saturation-based approaches.

\section{Numerical simulations}

In order to benchmark the performances of all these algorithms, the criteria presented in Section 2 is applied. All simulation are carried out using a motorcycle parameter set (see Remark 1). Note that in the following neither the Clipped approach (because of the nearly infinite way of adjusting) nor the MPC approach (complex to adjust due to multiple parameters, as well) will be simulated, but interested reader should refer to Tseng and Hedrick (1994); Giorgetti et al. (2006).

\subsection{Frequency domain analysis}

First, let compare the frequency responses of $F_{z}$, the transfer between $z_{r}$ and $z$ (comfort), and $F_{z_{\text {deft }}}$, the transfer from $z_{r}$ to $z_{\text {deft }}=z_{t}-z_{r}$. On Figure 8, the SH 2-states,
SH linear (with $\alpha=0$ ), ADD and PDD are compared with the passive ones with either $c_{\min }$ or $c_{\max }$, illustrating to attenuate well the $F_{z}$ transfer while degrading the $F_{z_{d e f t}}$ one.

Similarly, Figure 9 compares the performance attenuation of the two road-holding control laws, namely, GH 2-states and GH linear (with $\alpha=0$ ) with the passive ones with either $c_{\min }$ or $c_{\max }$.

It clearly emphasizes the improvement on $F_{z_{d e f_{t}}}$ while degrading the $F_{z}$ one. Moreover, it confirms the observation made in Morselli and Zanasi (2008) concerning the performances of the ADD and the PDD approaches.

Finally, the Mixed SH-ADD with $\alpha$ adjusted to $20 \mathrm{rad} / \mathrm{s}$ (to set the frequency range selector around $3 \mathrm{~Hz}$, the frequency where SH and ADD are switched) and "LPV semiactive" (with either a comfort or road-holding adjustment) frequency responses are compared to the passive cases on Figure 10 .

On this last figure, it is interesting to notice that the SH-ADD approach provides very good results in term of comfort performances. Concerning the LPV semi-active one, the two configurations tested (one focussing on comfort, and the other on road-holding) shows the large flexibility of the approach. In the next subsection, all these approaches are gathered and compared to the passive and optimal performances, using the index defined in Section 2 , providing a more synthetic picture of the semi-active suspension trade-off.

\subsection{Performance indexes $\&$ trade-off analysis}

Since improvement in one criteria implies a deterioration on the other, the performance index introduced in Section 2 is also evaluated for each control strategy. On Figure 11, all the performance indexes are compared to the passive with three configurations: $c=\left\{c_{\min }, 1500, c_{\max }\right\}$ (note that $c=1500$ has been selected as the nominal reference value since it provides a nice compromise between comfort and road-holding). 

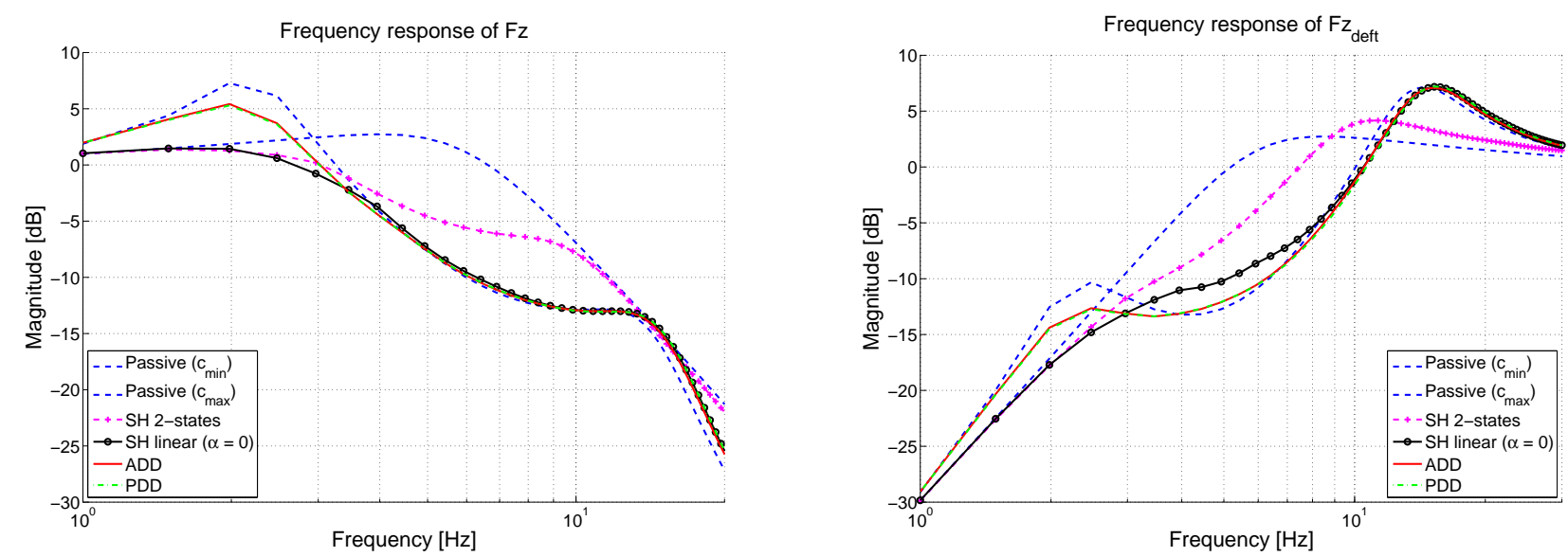

Figure 8: Comfort oriented control law frequency response $F_{z}$ (left) and $F_{z_{d e f}}$ (right).
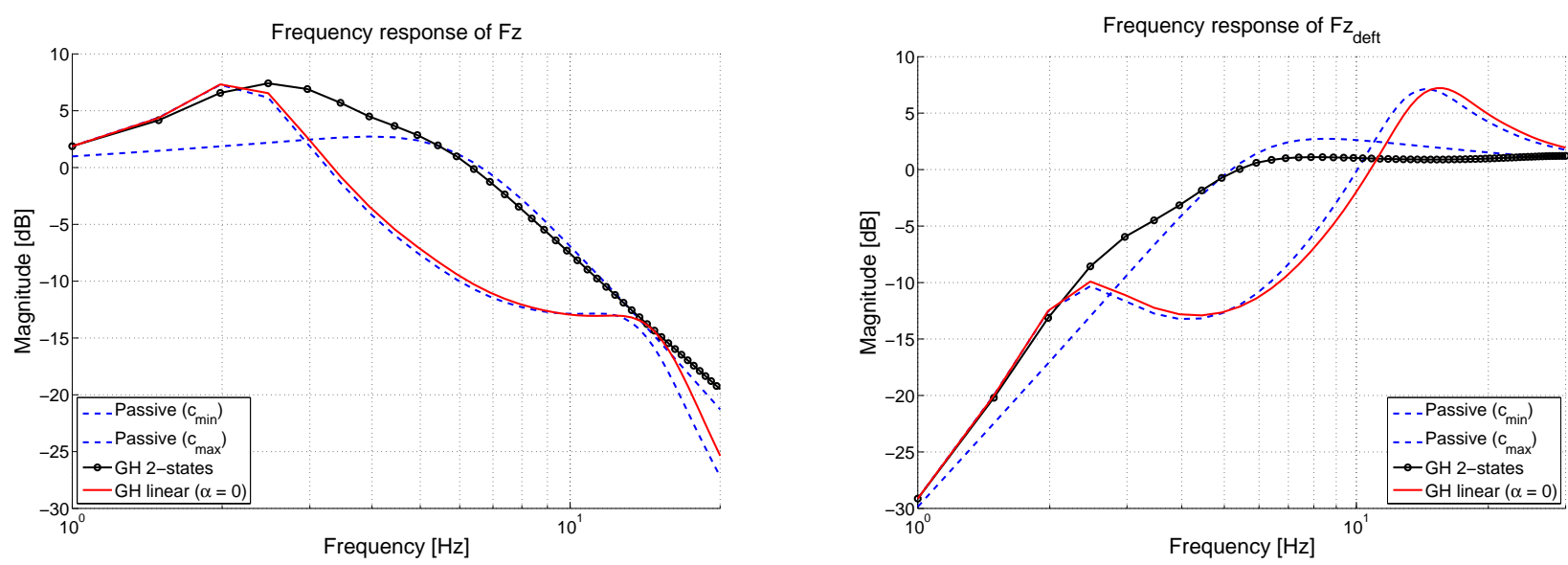

Figure 9: Road-holding oriented control law frequency response $F_{z}$ (left) and $F_{z_{\text {deft }}}$ (right).
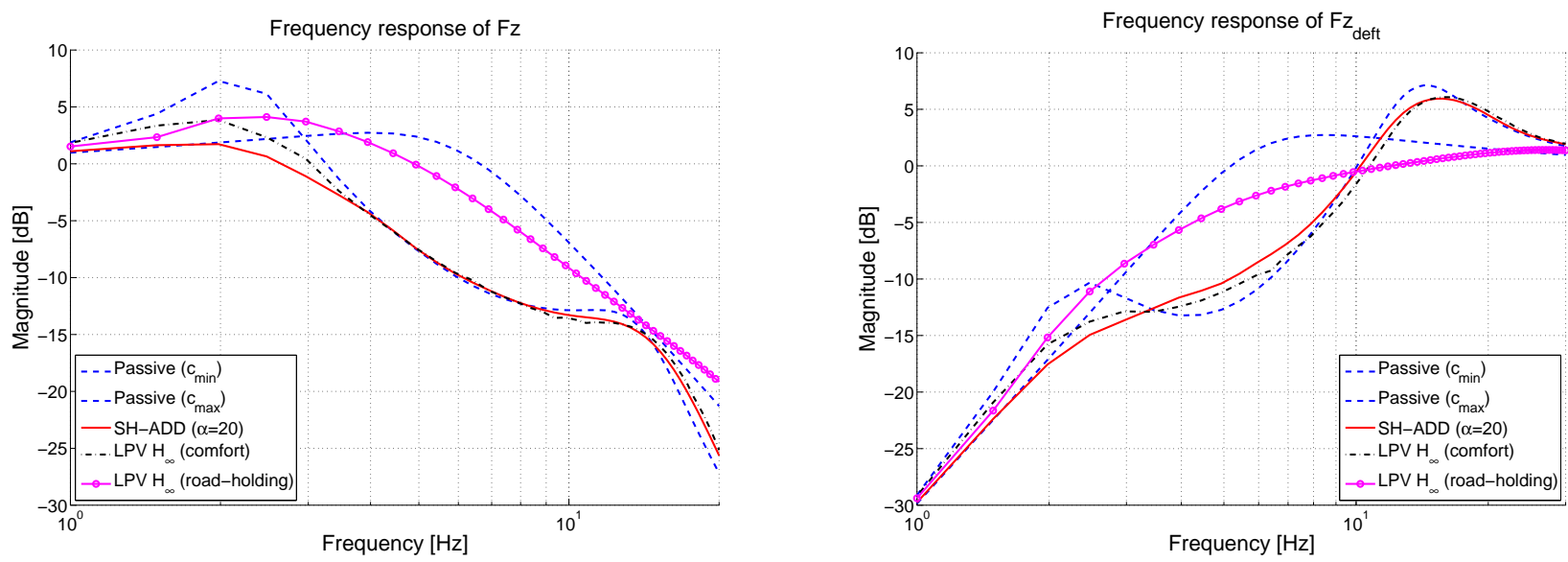

Figure 10: Road-holding oriented control law frequency response $F_{z}$ (left) and $F_{z_{\text {def }}}$ (right). 

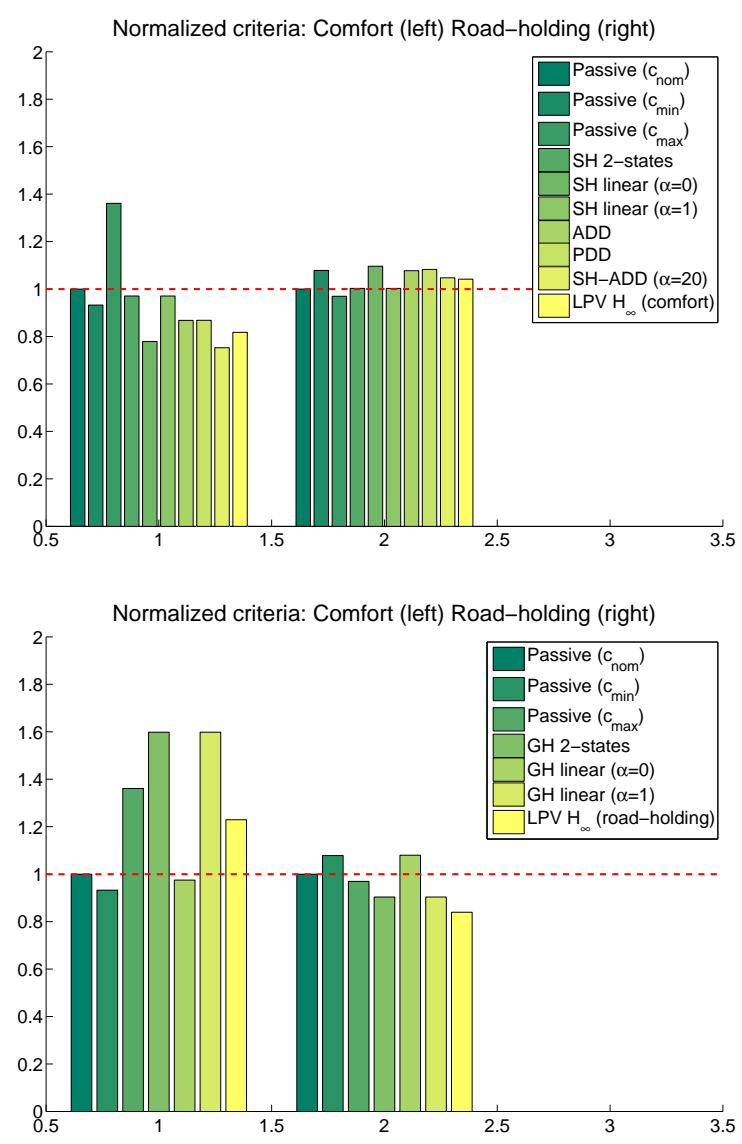

Figure 11: Normalized performance criteria comparison for different comfort (resp. road-holding) oriented control strategies. Comfort criteria - when cost function is $J_{c}$ (left histogram set) and RoadHolding criteria - when cost function is $J_{r h}$ (right histogram set).

In order to be even more precise, on Figure 12, the trade-off between comfort and road-holding is illustrated for all the previous strategies using a diagram with Comfort in the $\mathrm{x}$-axis and Road-holding in the $\mathrm{y}$-axis. This figure also includes the criteria evaluation for a passive suspension with damping varying from $c=100 \mathrm{~N} / \mathrm{m} / \mathrm{s}$ to $c=10000 \mathrm{~N} / \mathrm{m} / \mathrm{s}$ and the optimal bound numerically computed using the optimization framework presented in Section 3 .

The interesting point of this diagram is that (i) it illustrates the interest of the control to enhance the passive performances, (ii) shows the optimal performances of the SH-ADD approach in term of comfort (blue cross close to the optimal bound, in dashed red) and (iii) emphasizes the interest of the flexible LPV semi-active rule, allowing to achieve either good comfort performances (red leftoriented triangle) or road-holding ones (blue right-oriented triangle).

\section{Technology remarks and conclusions}

\subsection{Technological issues}

The technological aspects of semi-active suspension systems have been purposely overlooked, to emphasize the methodological contribution of this work. The most significant technological open-problems in semi-active suspensions systems today can be concisely summarized as follows:

- Actuation technology. Even if electro-hydraulic systems based on solenoid valves are the most used, Magneto-Rheological and Electro-Rheological systems are expected to grow in the near future. The semiactive control algorithms presented in this work however are only weakly dependent on the specific technology (see Lozoya-Santos et al. (2011)).

- Sensors configuration. This is a key issue since it has a large impact on the system costs (including maintenance costs). The main trend today is to move to classical configuration with two sensors per-axle (two accelerometers or an accelerometer plus a stroke sensor) to single-sensor configurations, where the second sensor is reconstructed using sophisticated filtering techniques. Another unstoppable trend is the attempt to re-use semi-active-suspensions sensors for other control subsystems (like rollover control, stability control, etc.).

- Transient-conditions. Even if the bulk of semi-active control algorithms has been developed and designed for "quasi-steady-state" conditions (no hard acceleration or braking; no hard steering), semi-active technology is fully exploited only if the whole manifold of working conditions is considered. A lot of research activity today is focused on the optimal management of transient working conditions, where semi-active technology can fruitfully assist other control subsystems like Electronic Stability Control, Traction Control and Anti-lock Braking Systems.

\subsection{Conclusions}

This paper is devoted to the survey of some semi-active suspension control algorithms. More specifically, the contribution of the paper are three-folds: first (i), a complete analysis of the structural properties of the considered single-corner model is done, then (ii), based on a comprehensive frequency domain-based performance metrics both road-holding and comfort optimal performances are investigated, emphasizing the inherent trade-off of this specific system. To this aim the suspension is modelled as the wellknown single-corner system and an optimisation problem is defined, based on the theory of Model Predictive Control, and using recent efficient tools from the Mixed Integer Programming. Finally, (iii) a benchmark of the main semi-active suspension control strategies is provided. The proposed benchmark is of course not exhaustive but still 


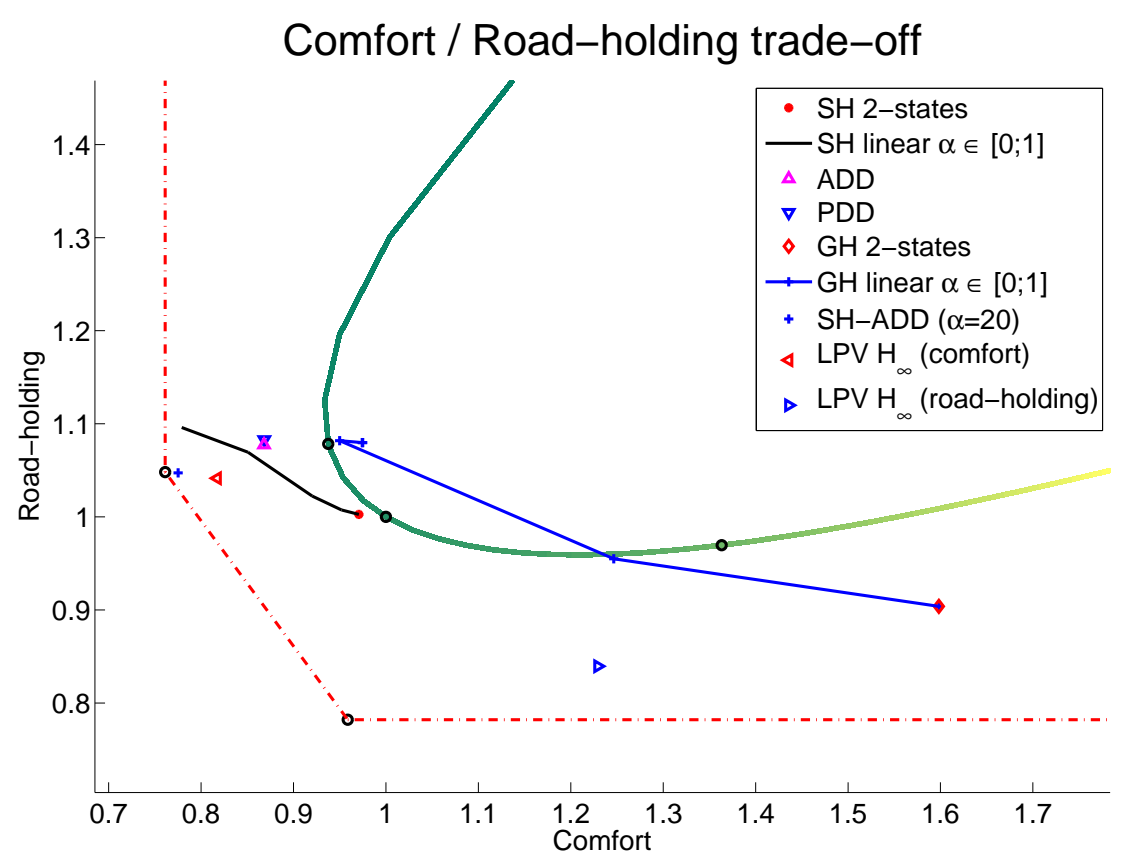

Figure 12: Normalized performance criteria trade-off for the presented control algorithms, compared to the passive suspension system, with damping value $c \in\left[c_{\min } ; c_{\max }\right]$ (solid line with varying color), optimal comfort and road-holding bounds (red dash dotted).

provides a good overview of the developed methods. The interest of the recent dedicated semi-active suspension approach (such as SH-ADD), presenting a low complexity, while providing great comfort performances, is illustrated. Nevertheless, other approaches (such as LPV semi-active, or Hybrid MPC) show some interests in the fact that they are quite flexible, but far more complex to adjust and implement. The proposed benchmark also include a complete evaluation of the passive suspension.

According to the authors, the main interest of the presented results relies in the definition of a complete methodology to benchmark any of semi-active control algorithms. The present works may then easily be extended to more sophisticated semi-active suspension model.

\section{Acknowledgement}

This work was partially supported by the MIUR project "New methods for Identification and Adaptive Control for Industrial Systems".

\section{References}

Ahmadian, M., Reichert, B., 2001. System Nonlinearities Induced by Skyhook Dampers. Shock and Vibration 8 (2), 95-104.

Ahmadian, M., Song, X., Southward, S., October 2004. No-jerk skyhook control methods for semiactive suspensions. Transactions of the ASME 126, 580-584.

Bemporad, A., Borrelli, F., Morari, M., September 2003a. MinMax control of constrained uncertain discrete-time linear systems. IEEE Transaction on Automatic Control 48 (9), 1600-1606.
Bemporad, A., Morari, M., Dua, V., Pistikopoulos, E., January 2003b. The explicit linear quadratic regulator for constrained systems. Automatica 38 (1), 3-20.

Borrelli, F., Baotic, M., Bemporad, A., Morari, M., June 2003. An efficient algorithm for computing the state feedback optimal control law for discrete time hybrid systems. In: Proceedings of the IEEE American Control Conference (ACC). Denver, Colorado, USA, pp. 4717-4722.

Caponetto, R., Diamante, O., Fargione, G., Risitano, A., Tringali, D., 2003. A soft computing approach to Fuzzy Sky-Hook control of semi-active suspension. IEEE Transaction on Control System Technology 11 (6), 786-798.

Choi, S., Nam, M., Lee, B., 2000. Vibration Control of a MR Seat Damper for Commercial Vehicles. Journal of Intelligent Material Systems and Structures 11, 936-944.

Chrzan, M., Carlson, D., 2001. Mr fluid sponge devices and their use in vibration control of washing machines. In: Proceedings of SPIE. Newport Beach, CA, pp. 370-378.

Codeca, F., Savaresi, S. M., Spelta, C., Montiglio, M., Ieluzzi, M., 2007. Semiactive control of a secondary train suspension. In: IEEE/ASME International Conference on Advanced Intelligent Mechatronics.

Deprez, K., Moshou, D., Anthonis, J., Baerdemaeker, J. D., Ramon, H., 2005. Improvement of vibrational comfort on agricultural vehicles by passive and semi-active cabin suspensions. Computers and Electronics in Agriculture 49, 431 - 440.

Do, A. L., Gomes da Silva Jr., J. M., Sename, O., Dugard, L., December 15-17 2011a. Control design for LPV systems with input saturation and state constraints: an application to a semi-active suspension. In: the 50th IEEE Conference on Decision and Control (CDC). Orlando, Florida, USA.

Do, A. L., Sename, O., Dugard, L., June 30 - July 2 2010. An LPV control approach for semi-active suspension control with actuator constraints. In: Proceedings of the IEEE American Control Conference (ACC). Baltimore, Maryland, USA, pp. 4653 - 4658.

Do, A. L., Sename, O., Dugard, L., Soualmi, B., September 2011b. Multi-objective optimization by genetic algorithms in $\mathcal{H}_{\infty} / \mathrm{LPV}$ control of semi-active suspension. In: Proceedings of the 18th 
IFAC World Congress (WC). Milan, Italy.

Du, H., Sze, K. Y., Lam, J., May 2005. Semi-active $\mathcal{H}_{\infty}$ control with magneto-rheological dampers. Journal of Sound and Vibration 283 (3-5), 981-996.

Geurts, P., Ernst, D., Wehenkel, L., 2006. Extremely randomized trees. Machine Learning 63 (1), 3-42.

Giorgetti, N., Bemporad, A., Tseng, H., Hrovat, D., May 2006. Hybrid Model Predictive Control Application Toward Optimal Semiactive Suspension. International Journal of Control 79 (5), 521533.

Giua, A., Melas, M., Seatzu, C., Usai, G., April 2004. Design of a Predictive Semiactive Suspension System. Vehicle System Dynamics 41 (4), 277-300.

GLPK, 2009. GLPK - GNU Linear Programming Kit. URL http://www.gnu.org/software/glpk/

Guardabassi, G., Savaresi, S. M., 2001. Approximate Linearization via Feedback - an Overview. Automatica 27 (1), 1-15.

Hong, K. S., Sohn, H. C., Hedrick, J. K., 2002. Modified skyhook control of semi-active suspensions: A new model, gain scheduling, and hardware-in-the-loop tuning. ASME Journal of Dynamic Systems, Measurement, and Control 124 (1), 158-167.

Hrovat, D., October 1997. Survey of advanced suspension developments and related optimal control application. Automatica 33 (10), 1781-1817.

Karnopp, D., Crosby, M., Harwood, R., 1974. Vibration Control Using Semi-Active Force Generators. Journal of Engineering for Industry 96, 619-626

Kiencke, U., Nielsen, L., 2000. Automotive Control Systems. Springer-Verlag.

Liao, W., Wang, D., 2003. Semiactive Vibration Control of Train Suspension Systems via Magnetorheological Dampers. Journal of Intelligent Material Systems and Structures 14 (3), 161-172.

Lofberg, J., 2004. YALMIP : A Toolbox for Modeling and Optimization in MATLAB. In: Proceedings of the CACSD Conference. Taipei, Taiwan.

URL http://control.ee.ethz.ch/ joloef/yalmip.php

Lozoya-Santos, J., Morales-Menendez, R., Sename, O., Dugard, L. Ramirez-Mendoza, R., Tudon-Martinez, J.-C., August 2011. Control Strategies for an Automotive Suspension with a MR Damper. In: Proceedings of the 18th IFAC World Congress. Milano, Italy.

Margolis, 1983. Semi-active control of wheel hop in ground vehicles. Vehicle System Dynamics 12 (6), 317-330.

Moreau, X., February 1995. La dérivation non entière en isolation vibratoire et son application dans le domaine de l'automobile. la suspension crone : du concept à la réalisation (in french). Ph.D. thesis, Université de Bordeaux I.

Morselli, R., Zanasi, R., 2008. Control of a port hamiltonian systems by dissipative devices and its application to improve the semiactive suspension behavior. Mechatronics 18, 364-369.

Oustaloup, A., Moreau, X., Nouillant, M., 1996. The CRONE suspension. Control Engineering Practice 4 (8), 1101-1108.

Poussot-Vassal, C., September 2008. Robust Multivariable Linear Parameter Varying Automotive Global Chassis Control. PhD thesis, Grenoble INP, GIPSA-lab, Control System dpt., Grenoble, France.

Poussot-Vassal, C., Savaresi, S. M., Spelta, C., Sename, O., Dugard, L., December 2010. A Methodology for Optimal Semi-Active Suspension Systems Performance Evaluation. In: Proceedings of the 49th Conference on Decision and Control. Atlanta, Georgia, USA, pp. 2892-2897.

Poussot-Vassal, C., Sename, O., Dugard, L., Gáspár, P., Szabó, Z., Bokor, J., December 2008. A New Semi-active Suspension Control Strategy Through LPV Technique. Control Engineering Practice 16 (12), 1519-1534.

Poussot-Vassal, C., Spelta, C., Sename, O., Savaresi, S., Dugard, L., August 2011. Survey on Some Automotive Semi-Active Suspension Control Methods: a Comparative Study on a Single-Corner Model. In: Proceedings of the 18th IFAC World Congress. Milan, Italy, pp. 1802-1807.

Rossi, C., Lucente, G., April 2004. $\mathcal{H}_{\infty}$ control of automotive semiactive suspensions. In: Proceedings of the 1st IFAC Symposium on Advances in Automotive Control (AAC). Salerno, Italy.

Sammier, D., Sename, O., Dugard, L., April 2003. Skyhook and $\mathcal{H}_{\infty}$ control of active vehicle suspensions: some practical aspects. Vehicle System Dynamics 39 (4), 279-308.

Savaresi, S. M., Poussot-Vassal, C., Spelta, C., Sename, O., Dugard, L., 2010. Semi-Active Suspension Control Design for Vehicles. Elsevier - Butterworth Heinemann.

Savaresi, S. M., Siliani, E., Bittanti, S., 2005. Acceleration-DrivenDamper (ADD): an optimal control algorithm for comfort-oriented semi-active suspensions. ASME Transactions: Journal of Dynamic Systems 127 (2), 218-229.

Savaresi, S. M., Spelta, C., 2007. Mixed Sky-Hook and ADD: Approaching the Filtering Limits of a Semi-Active Suspension. ASME Transactions: Journal of Dynamic Systems, Measurement and Control 129 (4), 382-392.

Savaresi, S. M., Spelta, C., January 2009. A single-sensor control strategy for semi-active suspensions. IEEE Transaction on Control System Technology 17 (1), 143-152.

Sename, O., Dugard, L., September 2003. Robust $\mathcal{H}_{\infty}$ control of quarter-car semi-active suspensions. In: Proceedings of the European Control Conference (ECC). Cambridge, England.

Simon, D., 2001. An investigation of the effectiveness of skyhook suspensions for controlling roll dynamics of sport utility vehicles using magneto-rheological dampers. Ph.D. thesis, Virginia Polytechnic Institute and State University.

Sohn, H., Hong, K., Hedrick, J., September 25-27 2000. Semi-active control of the macpherson suspension system: Harware-in-theloop simulations. In: IEEE CCA 2000. Anchorage, Alaska, pp. 982-987.

Song, X., Ahmadian, M., Southward, S., November 2007. Analysis and strategy for superharmonics with semiactive suspension control systems. ASME Journal of Dynamic Systems, Measurement, and Control 129, 795-803.

Spelta, C., Previdi, F., Savaresi, S. M., Fraternale, G., Gaudiano, N., 2009. Control of magnetorheological dampers for vibration reduction in a washing machine 19, 410-421.

Spelta, C., Savaresi, S. M., Fabbr, L., November 2010. Experimental analysis and development of a motorcycle semi-active 1-sensor rear suspension. Control Engineering Practice 18, 1239-1250.

Tseng, H. E., Hedrick, J., 1994. Semi-Active Control Laws - Optimal and Sub-Optimal. Vehicle System Dynamics 23 (1), 545-569.

Unger, A., Schimmack, F., B. Lohmann, R. S., August 2011. Application of LQ based semi-active suspension control in a vehicle. In: Proceedings of the 18th IFAC World Congress. Milano, Italy.

Valasek, M., Kortum, W., Sika, Z., Magdolen, L., Vaculin, O., June 1998. Development of semi-active road-friendly truck suspensions. Control Engineering Practice 6 (6), 735-744.

Zin, A., Sename, O., Gaspar, P., Dugard, L., J.Bokor, October 2008. Robust LPV $-\mathcal{H}_{\infty}$ control for active suspensions with performance adaptation in view of global chassis control. Vehicle System Dynamics 46 (10), 889-912. 